\title{
Market Drivers for Materials and Process Development in the 21st Century
}

\section{F.R. Field III, J.P. Clark, and M.F. Ashby}

Economics has made us partners and necessity has made us allies. -John F. Kennedy

The true test of a brilliant theory is what first is thought to be wrong is later shown to be obvious.

-Assar Lindbeck (of the Nobel Prize Committee commenting on Franco Modigliani's award winning theory of Corporate finance)

\section{Science Push and Market Pull}

Materials are the "stuff" of engineering design. New materials inspire designers, but even more, design drives materials development. It is true that the most inspiring developments in engineering materials have emerged from scientific research into the structure of matter and its interaction with mechanical, electric, magnetic, and nuclear force fields, with radiation of all sorts, and with chemically different species. But for every dollar spent on inspirational research of this kind, a hundred dollars are spent on research of another kind: that driven by specific market needs. During the second half of the last century, the most potent drivers of this kind included the space race, nuclear power, the cold war, and the silicon-based computation revolution, to all of which the materials community responded appropriately. It is these that gave the field of materials much of its present momentum. But the drivers have now changed: The cold war has been superseded by competition of other sorts, and spending on both nuclear power and space has been scaled back. What has replaced them?

\section{The Inputs to Product Design}

Figure 1 suggests the strongest drivers to which today's designers seek to respond. While this figure is a gross simplification, it is a useful one upon which to structure this discussion. The four main factors upon which the designer relies when considering material choice are the relationship between material specification and (1) the Technical Performance of the product, (2) the Economic Performance of the product, (3) the Environmental Performance of the product, and

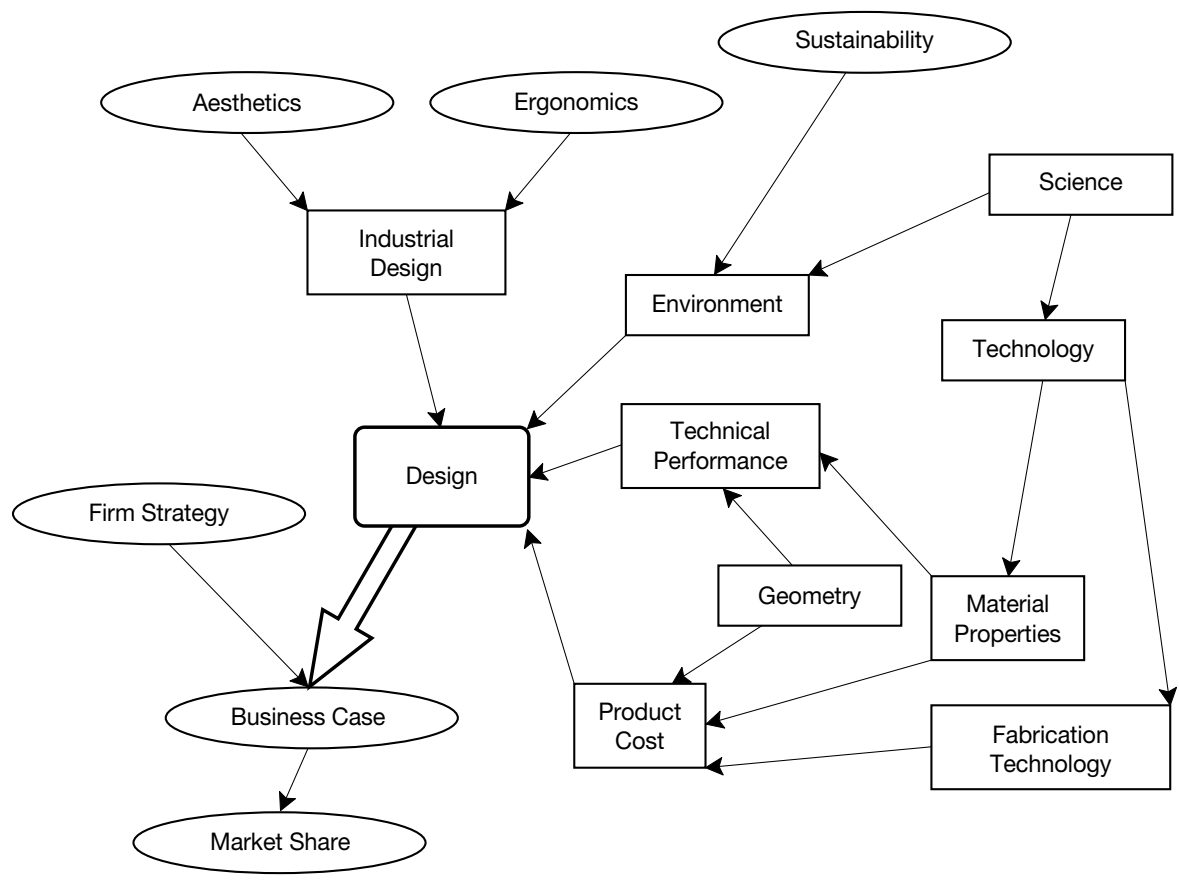

Figure 1. The driving forces that influence product design.

(4) the practice of Industrial Design embedded in the product and its functionality. Before turning to the consideration of these factors, it is worthwhile to explore briefly the way in which these performance metrics are ultimately employed by the designer. The existence of four main classes of information that drive materials specification (not to mention the myriad individual expressions of these objectives) suggests that the selection of a materials specification will require a careful balancing of the performance of the available alternatives. This sort of multiple objective decision-making is typical of most complex engineering decisions, but it is particularly so here because there is no simple transformation of one measure of performance into another. For example, to what extent does increased recyclability (an environmental performance criterion) offset an increase in product cost (an economic performance

Materials Challenges For The Next Century presents a series of articles speculating on the role of materials in society in the coming century and beyond. criterion)? More importantly, is the designer's judgment necessarily well enough informed to accurately reflect the product consumer's views in this regard?

\section{Utility Functions-The Tradeoff between Performance Metrics}

Economists have confronted this problem as they have worked out the general theory of consumer demand. Just as the economist employs a technological construct known as the production function to transform independent resources into a quantity of goods produced, so this function is employed to transform the disparate units of consumption (e.g., food, shelter, leisure) into a quantity of individual well-being. This function is known as the "utility function" and its sole purpose in the economic domain is to transform the objective magnitude of various kinds of consumption into a measure of wellbeing that can be used to explain consumer demand. ${ }^{1}$ Further, diversity of consumer preferences can be explained by asserting that utility functions are often unique to each consumer.

Interestingly, while economists have used utility as a purely theoretical construct, decision theorists have established 
that, for well-defined classes of multiple objective problems, the utility construct can be practically employed to study the way in which tradeoffs among objectives are done. Materials selection has been an area of particular interest to decision theorists and materials scientists, ${ }^{2,3}$ and it is useful to explore a simple example in order to illustrate both its explanatory and prescriptive value in this context.

The need for such a tool can be illustrated simply. A classic design decision in many engineering projects is the tradeoff between the mass of a product and its cost. Suppose, for example, that there are four possible designs, A through D, whose cost and mass are plotted in Figure 2.

Now, assuming that, all things held equal, less cost is preferred to more cost, and less mass is preferred to more mass, which design should be chosen? One way to approach the question is to work to eliminate the "foolish" alternatives. Design D is one such design. Design B offers exactly the same mass as $\mathrm{D}$ at a lower cost; clearly Design B is better than Design D. Design C is also a poor choice, in that Design B is both less costly and less massive. However, no such evaluation can be made upon consideration of Designs A and B. Design B is less massive, but more costly than Design A, confronting the designer with the need to establish whether cost or mass is more important when making the final design choice; without such a statement of strategic intent, it is impossible to eliminate one of the two remaining alternatives from consideration. And, while there may be certain engineering applications where all of the disparate design objectives can be resolved against one another or transformed into a single metric, the number of these applications is small.

Utility analysis, a branch of decision theory focused upon the application of the concepts of microeconomic utility, can be applied to such problems. While other transformations are commonly applied in this day of inexpensive computer processing power, only utility is supported by a strong body of theoretical knowledge as well as operational practicality. For example, while weighted indexing of product attributes is commonly employed, there is no general support for the functional form of the index employed, nor is there any satisfactory experimental basis given to defend it. Utility analysis, as a technique driven by theory and derived from experimental sources, avoids both of these pitfalls while providing important insights into the strategic intent underlying many operational design decisions-insights

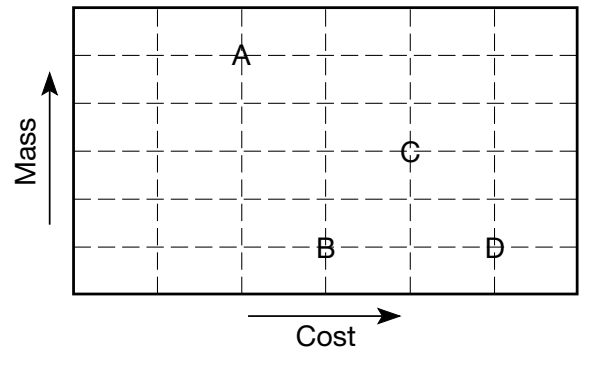

Figure 2. Four alternative designs

differing in mass and cost.

that can inform not only the designer, but also the materials developer.

A brief summary of an application of utility analysis illustrates this. Consider the comparative merits of four automobile bumper systems, with the ultimate intent to establish the competitive posture of one of the polymeric materials employed. A research plan is directed at understanding the way in which automobile bumper designers focused upon establishing the set of bumper performance criteria which were (1) influenced by material specification and (2) were determinants of bumper suitability in the minds of the bumper designers. Six characteristics, derived from interviews and engineering literature were selected for further study: (1) bumper cost, (2) bumper mass, (3) the distance the bumper deflected under design load, (4) bumper service life, (5) bumper performance in regulatory tests, and (6) bumper resistance to incidental impacts.

Bumper designers from major North American automobile OEMs were interviewed to establish their preferences, using standard techniques in utility analysis. A key result of this effort was the discovery that, of the six characteristics originally established for evaluation, only cost and mass were characteristics for which a range of levels of performance would actually be acceptable in the final

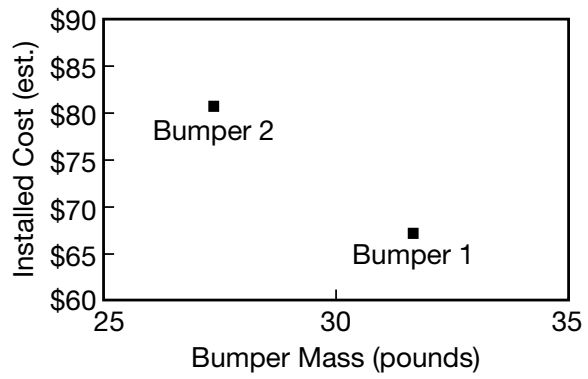

Figure 3. The mass and cost of two of the four bumpers. It is impossible to select between them without an estimate of the value associated with weight-saving. design. The other four characteristics, like many others that were eliminated from consideration, were far more closely constrained by the overall program teams, and designers were obliged to design to fixed specification instead of varying the performance according to designer choice; for these four, exceeding the fixed specification did not result in increased valuations of the product. Plotting two of the four bumper alternatives in cost-mass space yields Figure 3. No choice is possible here without a measure of the relative importance of cost and mass. However, the interview data enabled the researchers to calculate the combinations of cost and mass whose utility to the designer was equal to that of Bumper 1. Plotting those points yielded the line on Figure 4 .

The first result is that, as designed, Bumper 2 is inferior to Bumper 1. While this result was disappointing to the proponents of Bumper 2, it is also important to note that the distance from the line of constant utility measures the amount of improvement in cost and/or mass necessary to make Bumper 2 as good as Bumper 1 , and surpassing those targets will yield a bumper superior to Bumper 1. In this case, it turned out that such improvements, through the application of other mechanical elements, would allow Bumper 2 to meet those design targets, and this design (and its associated enabling materials) were widely used on several vehicle systems in the early 1980s.

More generally, this figure shows that, at the time of this study, there were some peculiar motivations for weight savings in place in the bumper design groups. The shape of the curve of constant utility (i.e., of combinations of cost and mass as "good" as the base case design) represents behavior that might be considered pathological; note that the upward-curving shape implies that the lighter the bumper, the more cost the designer is willing to incur to achieve the next increment of

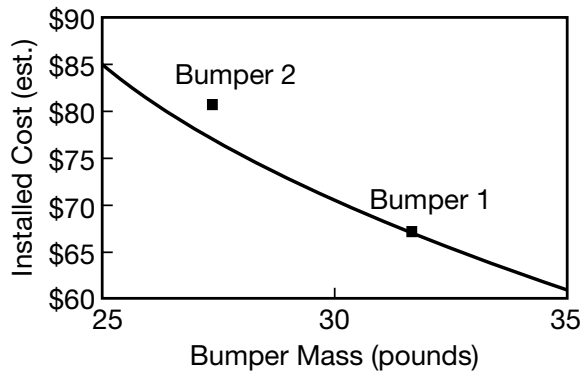

Figure 4. The equal-utility line shows that Bumper 1 is preferable to Bumper 2, but it also shows the reduction in its cost or mass that would reverse the position. 
weight saving. When this result was discussed with the bumper design groups, they confirmed this attitude toward weight reduction, to the surprise of their managers. Because of the nature of the design process across component groups, weight savings in structural applications was a focus of intergroup competition, and groups helping to meet aggressive weight reduction target (design "bogeys") were well rewarded. While such behavior may be counterintuitive, it was a key aspect of their design process, and these attitudes demonstrably led to material and design choices that would otherwise be unpredictable.

\section{Relationship between Design and Cost}

For large organizations, the design and the cost analysis functions have generally been divorced from one another, with communication channels largely confined to the mechanisms for developing and disseminating design rules and institutional policies. The segregation of these functions may have served important purposes in the past (e.g., establishing the impartiality of cost estimates), but this separation of functions has largely served to make cost a constraint under which designers chafe, rather than a product feature to be incorporated into the overall product development strategy.

A key obstacle to the incorporation of cost analysis into the classical design paradigm has been the lack of analytical tools that are parameterized along the same lines as the designer's engineering analysis tools, allowing the designers to evaluate explicitly the cost and functionality of their designs in a consistent fashion. In recent years, methods for estimating and analyzing the cost of manufacturing and using products have become more sophisticated ${ }^{4}$ but the tools for doing so are still in an early stage of development. The simplest method of cost estimation is to employ industry rules of thumb, based on past experience with designs, materials, and processes. Often these methods rely upon correlating materials properties (e.g., strength or stiffness) with raw material prices to make broad generalizations about the suitability of materials classes for particular applications. When used by experts with years of experience, rules of thumb can yield accurate measures of cost for products within the realm of experience of the estimator.

Another approach is to allocate factor costs (e.g., capital, labor, materials, and energy) from a manufacturing facility to particular products. For instance, one can relate the material content of a product to the time and equipment required to convert the purchased materials into the final product. A relatively new approach, activity-based costing, ${ }^{5}$ identifies each of the activities (or processes) in a manufacturing facility and allocates product costs according to the activity, rather than the capital or labor employed. This approach has been successful in enabling plant managers to better understand the relationship between the manufacturing process and the cost of the product. It is useful for analyzing the cost drivers for a given manufacturing facility, but less useful for predicting the cost variations associated with a change in design (materials, geometry, or process). A rough rule of thumb is that about $70-80 \%$ of the cost of a product is determined by the design; the remainder is a function of the efficiency of the manufacturing operation.

Activity-based costing does demonstrate that consideration of the process is the key factor when attempting to characterize costs. ${ }^{5}$ While activity-based costing examines processes from the perspective of how best to manage a process, the designer requires a different emphasis: How design choice-be it materials, processing, or geometry-influences cost, and how the resulting performance of the product is balanced best against that cost. In effect, a more robust, process-based cost-estimation methodology is necessary to analyze these situations.

A process-based approach, called technical cost modeling, is finding increasing use. ${ }^{4}$ Technical cost modeling requires that the different cost elements for each processing step be estimated separately based on the physics of the manufacturing process, and specified economic and accounting assumptions.

The key principles of technical cost analysis are as follows:

- The total cost of a process is made up of many contributing elements that can be classified as either fixed or variable, depending upon whether they are affected by changes in the production volume. Usually, the main elements of fixed cost are main machine cost, tooling cost, and overheads. Variable cost includes raw and process materials, direct labor, and energy. A detailed description of the estimation of fixed and variable cost and the methods for distributing them over the total number of components manufactured can be found in Reference 6 .

- Each cost element can be analyzed to establish the factors that affect its value. For example, heat-transfer rates and chemical-reaction rates can affect the cycle time or production rate of a process. The effects of these factors depend not only on the process but also on the part being produced. Thus, the cost elements of the manufactured part can be analyzed in terms of cycle time requirements, which in turn can be analyzed in terms of engineering process information.

- Total cost can be estimated from the sum of the elements of cost for each contributing process. The technical cost approach essentially reduces the complex problem of cost analysis to a series of simpler estimating problems, and brings engineering expertise, rather than intuition, to bear on solving these problems. This is extremely important in complex manufacturing situations such as the printed circuit board fabrication or assembly of an automotive body, which comprise many unit operations.

One advantage of technical cost modeling over simpler cost estimating techniques is that it not only provides an estimation of the total cost, but also provides a breakdown of the cost of each contributing element. This information can be used to direct efforts at cost reduction, or it can be used to perform sensitivity analyses, identifying the cost consequences of specific modifications in the design of a product.

A disadvantage of the approach has been that it is time-consuming and expensive to construct such models from scratch. This drawback is of less importance at this time because an inventory of 40-60 materials-processing operations (e.g., stamping, hydroforming, and injection molding) has been built and is being used by a number of firms to explore changes in early stage designs. Some have titled this exercise "virtual design cost analysis" because the idea is to have a good estimate of the cost of alternative designs before the expensive detailed designs are completed.

Technical cost models are currently being used in conjunction with other simulation models in materials science. For instance, when simulating the cycle time of a polymer injection molding, we need to know both the time to fill the mold and the time to cool the part. If more detailed design data are available, a finite element methodology (Mold Flow) can be used to model the pressure that develops in the part and the fill time.

As an example, consider the problem of projecting the cost of a component made from a new class of materials-aluminumbased metal foam-from that of current pilot-scale production to that made possible by large-scale mass production. There are, at present, several competing processes for making and shaping metal foams. Three of the most promising are:

- liquid-state foaming of aluminum, 
- $\mathrm{TiH}_{2}$ expansion using powder metallurgical processing as a batch process, and - $\mathrm{TiH}_{2}$ expansion using powder metallurgical processing as a continuous process. Cost models for each include sub-models to capture the effect of component size on production rate, the die and equipment costs, allowance for scrap, die-life, and capital write-off. Details of the processes and the cost models can be found in References 7 and 8.

The outputs of the models (Figures 5 and 6) show the way in which the cost of the manufactured component depends on

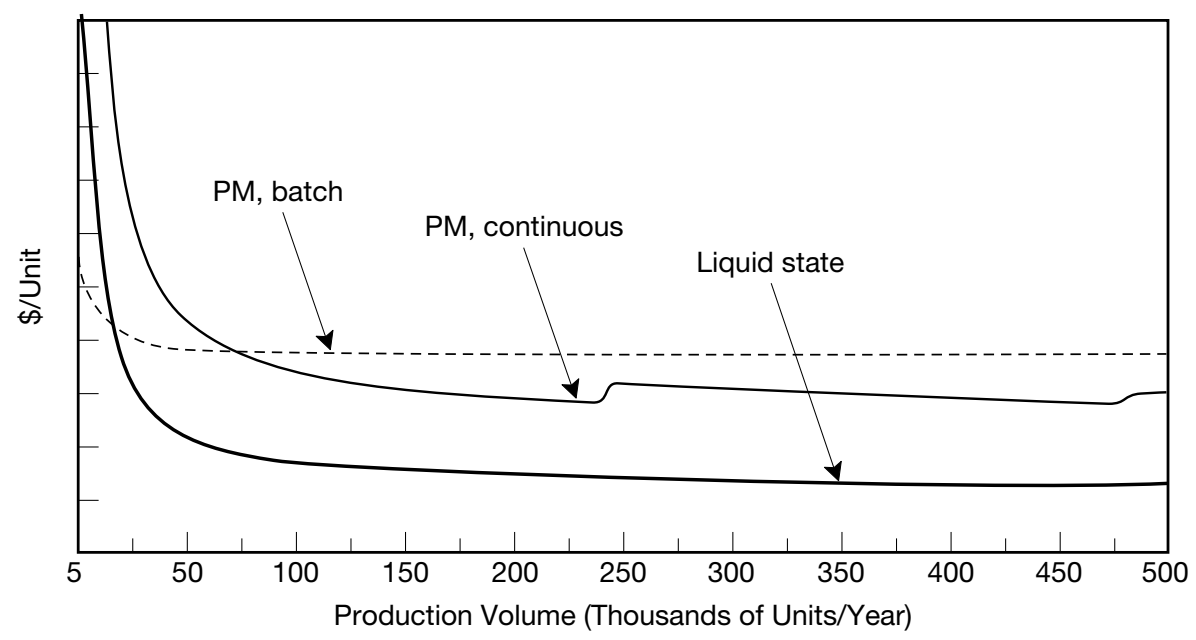

Figure 5. Production costs for processing of aluminum foam by three methods.

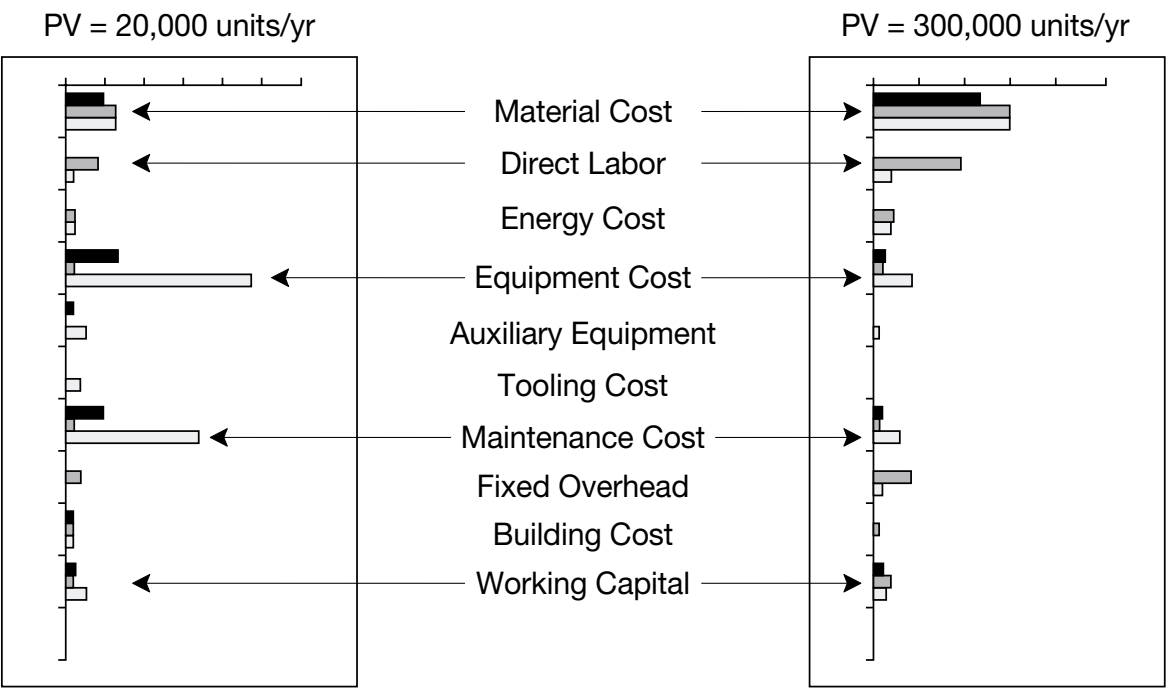

Liquid $\square \mathrm{PM}$, batch $\square \mathrm{PM}$, continuous

Figure 6. Line item cost for crossover annual production volume of 20,000 and 70,000 units: processing of aluminum foam by three methods.

production volume and also identify cost drivers. In this instance the batch powder metallurgical (PM) process is the most economical option for annual production volumes of up to 20,000 parts. Figure 6, which shows a snapshot of the line item costs for each process at 20,000 and 300,000 parts per year, reveals that fixed costs, in particular equipment costs, drive the low volume cost of both continuous PM processing and liquid-state processing rather than that of batch PM processing. In this way, the cost model can be used to aid the decision about the suitability of converting to a

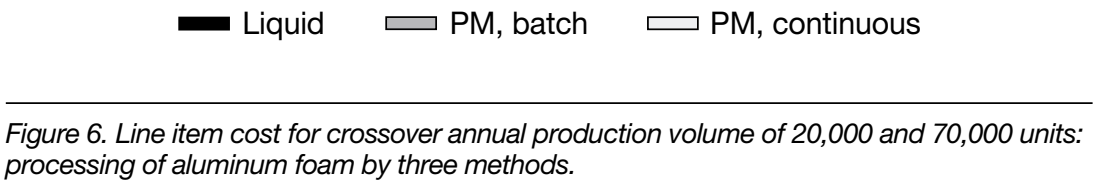

continuous process. By comparing the cheapest aluminum foam component (at the required production volume) with an incumbent material for any given application, the cost differential between a new and an incumbent material solution can be established, providing inputs to the utility analysis of the next section.

\section{Science and Technology Drivers}

The least predictable of the driving forces for a change is that of science itself. Despite periodic predictions that science is "coming to an end," expose new concepts and phenomena. These translate into new technology, creating new materials with both technical and aesthetic potential.

In tonnage terms, the use of materials for structural purposes overwhelmingly dominates. Steel, concrete, asphalt, brick, and wood account for more than $95 \%$ of all the materials we consume, and the scale of their consumption is enormous. These and most other bulk structural materials (aluminum alloys, commodity polymers and composites) are now technically mature, evolving only slowly. The main drivers for change here are economic, focusing on improved processing to reduce cost and variability.

On a smaller structural scale, the picture is rather different. Techniques for making nanostructured materials - metals, ceramics, and polymers-have emerged from recent research and reveal mechanical, electrical, magnetic, and optical properties that are sufficiently attractive to stimulate large-scale development programs. The key concept here is the importance of material length scales; when the length scale characterizing the microstructure becomes comparable with that of other phenomena-wavelengths of electrons, phonons or other excitations, coupling lengths, magnetic domain sizes, dislocation or flux line spacings, or even just the physical dimensions of the component itself-then strongly nonlinear interactions result. The potential this offers for ultrahigh strength, for information storage, for unique magnetic and optical behavior are major drivers, deriving directly from new scientific discoveries.

Advances and understanding in the biosciences is stimulating deeper exploration of biomaterials - both synthetic materials for medical applications and materials derived from natural sources. The stimulus here comes partly from the health-care sector, partly from the environmental sector, and partly from the perception thatwith new understanding and characterization techniques-there is much to be learnt from the way in which nature has 
solved her materials problems.

In a similar way, the perceived potential of electroactive and optoactive polymers is driving large-scale material-development programs. Here the vision-already realized in some cases-is that of ultra-efficient light sources, of flexible displays using light-emitting polymers (LEPs), and of flexible film or fibers with sensing and information-processing capability, spawning new industries exploiting these in fabrics and clothing. Ceramic science, too, has delivered new materials with perceived potential: nonmetallic magnets that offer high fields but are electrically insulating, enhanced piezoelectric behavior for actuation and sensing, and diamondlike films and fibers with attractive mechanical and semiconducting properties.

Supporting all of these are developments in the modeling, particularly the computer modeling, of materials. Modeling at the atomic scale allows the design of polymer molecules with predefined properties and the catalysts needed to make them, techniques exploited commercially in industries as different as that of pharmaceuticals and that of bulk polyolefin production. Modeling that links phenomena at differing length scales helps predict how macroscopic properties depend on chemistry and structure at the molecular scale. Any developments in topological and parametric optimization allow the development of more efficient multimaterial systems.

A full analysis of new developments in the science of materials is beyond the scope of this article. But it will be clear from the examples just given that science remains a fertile source of new materials, driving the large development programs required to exploit their novel properties.

\section{The Environment and Sustainability}

All human activity has some impact on the environment. The environment has a certain capacity to cope with this so that a certain level of impact can be absorbed without lasting damage. But it is clear that present-day activities frequently exceed this threshold, diminishing the quality of the world in which we now live and threatening the well-being of future generations. ${ }^{0,11}$ The position is dramatized by the following statement: At a global growth rate of $3 \%$ per year we will mine, process, and dispose of more stuff in the next 25 years than in the entire history of humankind. Design for the environment is generally interpreted as the effort to adjust our present lifestyle to correct known, measurable, environmental degradation; the time scale of this thinking is 10 years or so. Concern for sustainability is the longer view: adaptation to a lifestyle that meets present needs without compromising the needs of future generations. The time scale here is longer-perhaps 50 years into the future.

The materials life cycle is sketched in Figure 7. Ore and feedstock, most of them nonrenewable, are processed to give materials; these are manufactured into products that are used and at the end of their lives, recycled or committed to incineration or landfill. Energy is consumed at each station in this circuit, with an associated penalty of $\mathrm{CO}_{2}$ and other emissions-gaseous, liquid, and solid. The problem, crudely put, is that the sum of these exceeds the capacity of the environment to absorb them. The visible injury is mostly local, and its origins can be traced and remedial action taken. Much environmental legislation aims at modest corrective action; a 10\% change in, say, the average gasoline consumption of cars is seen as very significant.

Sustainability requires solutions of a completely different kind. Even conservative estimates of the changes needed to restore long-term equilibrium with the environment envisage a reduction in the flows of Figure 7 by a factor of four; some say $10 .{ }^{11,12}$ Population growth and the growth of the expectations of this population more than cancel any $10 \%$ savings that the developed nations may achieve. It looks like a tough problem, one requir- ing difficult adaptation, and one to which no answers will be found here. But it remains one of the ultimate boundary conditions to be retained as background to any creative thinking.

How, then, do we respond to the nearer term problem? The most obvious ways to conserve materials are to make products smaller, make them last longer, and recycle them when they finally reach the end of their lives. But the seemingly obvious can sometimes be deceptive. Materials and energy form part of a complex and highly interactive system, of which Figure 8 illustrates. Here, primary catalysts of consumption such as new technology, deliberate obsolescence, increasing wealth and education, and population growth influence aspects of product use and through these, the consumption of materials and energy and the by-products that these produce. The connecting lines indicate influences; a plus sign suggests a positive, broadly desirable influence; a minus sign suggests a negative, undesirable influence, and a plus-minus pair suggests that the driver has the capacity for both positive and negative influences.

The diagram brings out the complexity. Follow, for instance, the lines of influence of New technology and its consequences. It offers more material and energy-efficient products, but by also offering new functionality it creates obsolescence and the desire to replace a product that has useful

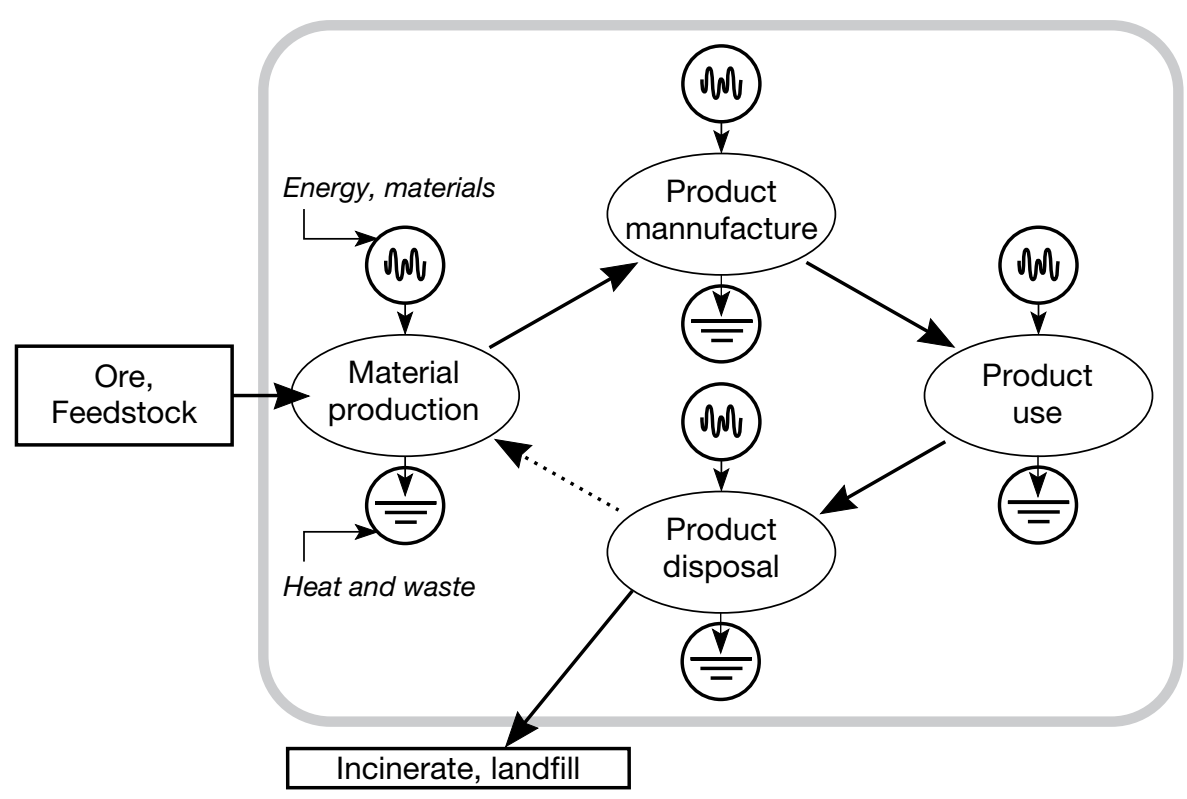

Figure 7. The materials life-cycle. Ore and feedstock are mined and processed to give a material. This is manufactured into a product that is used and, at the end of its life, discarded or recycled. Energy and materials are consumed in each phase, generating waste heat and solid, liquid, and gaseous emissions. Circles with sine waves are sources, and with parallel lines are sinks. 


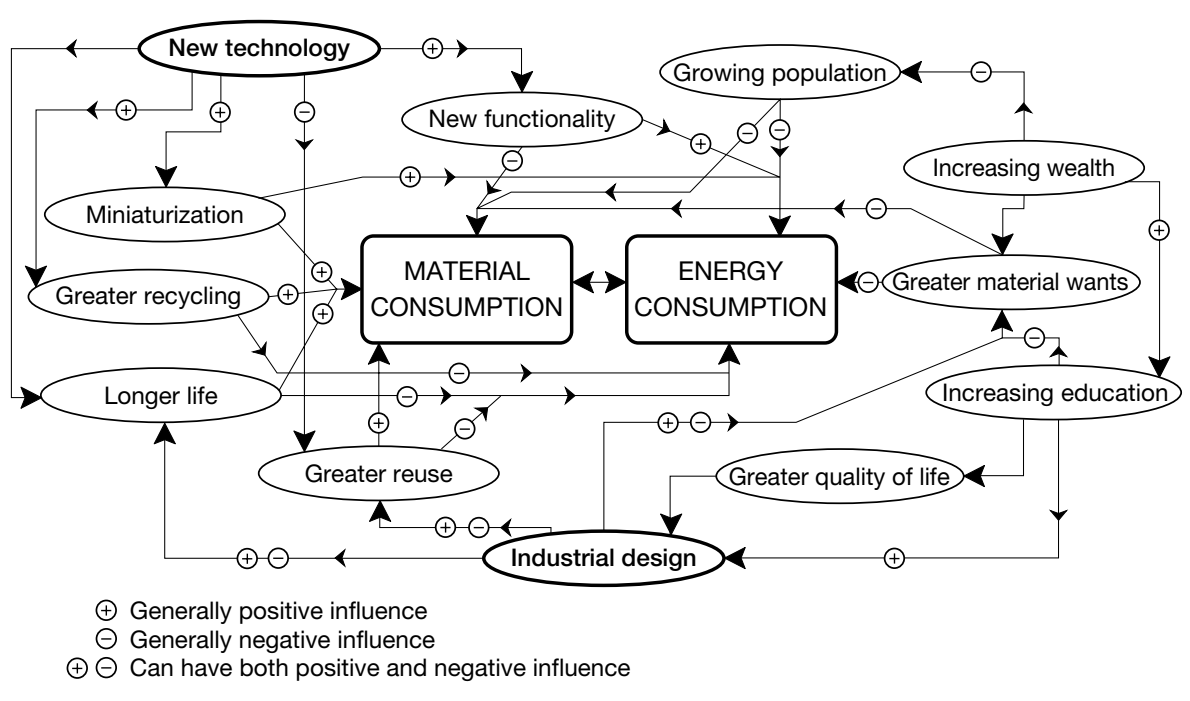

Figure 8. The influences on consumption of materials and energy.

life left in it. Electronic products are prime examples of this: $80 \%$ are discarded while still functional. And observe, even at this simple level, the consequences of Longer life - a seemingly obvious measure. It can certainly help to conserve materials (a positive influence) but, in an era in which new technology delivers more energyefficient products (particularly true of cars, electronics, and household appliances today), extending the life of old products can have a negative influence on energy consumption.

As a final example, consider the bivalent influence of industrial design. The lasting designs of the past are evidence of its ability to create products that are treasured and conserved. But today it is frequently used as a potent tool to stimulate consumption by deliberate obsolescence, creating the perception that "new" is desirable and that even slightly "old" is unappealing.

The single most powerful driver for materials development here is that of environmental legislation. Early environmental regulation focused upon "end of pipe" strategies to remediate environmental effects. Today, members of both the environmental and the engineering community adopt a more enlightened approach, exploring product design strategies that eliminated the need to produce the environmental effect in the first place. This view has led to what is now known as product policy, rather than process policy - a focus upon the ways in which a product's functionality can be achieved and attempting to characterize the relative merits of each of the alternatives.

The analytical handmaiden of product policy is life cycle analysis (LCA), a method originally proposed by the Society of Environmental Toxicology \& Chemistry. ${ }^{13}$ This method constitutes an analytical framework within which the environmental effects of a product (or, more formally, a functional unit) can be counted, essentially constructing a framework for accounting for the myriad environmental effects arising from society's efforts to produce, utilize, and dispose of the manufactured instruments of function. LCA puts materials selection squarely in the center of many environmental questions simply because of the pervasive effect of materials choice upon the performance of a product, the materials-processing technologies available to manufacture and recycle products, and the chemistry of materials extraction and refining. While concepts like toxicity and other direct challenges to human health and safety remain fully accounted within the LCA framework, the primary contribution of the method has been to extend the scope of design concern into new areas that were only occasionally, if ever, treated by product developers. While there is much to be done to improve the method, the studies that have been done over the past decade have led to two broad classes of environmental effect which are at the heart of most environmental evaluations of materials choice today. These two areas are (1) resource depletion and (2) environmental releases or emissions.

\section{Resource Depletion}

The materials used today derive from natural resources that are extracted from the environment. These resources, whose value is determined in the marketplace, are used to make products. Once these resources have been extracted, they are no longer available for future generations to employ, suggesting that there is an opportunity cost that should be associated with their extraction. In general, resource depletion arguments center around the idea that the opportunity cost of resource extraction is greater than the market price that is associated with resources, implying that resources are being extracted too quickly. They point to the fact that real prices of natural resources have steadily declined to demonstrate the argument that industrialized production is generally wasteful of natural resources, and that an extra-market measure of depletion should be employed to slow the current rates of extraction.

LCA enables the engineer to quantify the rate of extraction, but does little to establish what the appropriate rate should be, or the appropriate price of a resource. It does, however, establish the extent to which resources become reavailable at the end of a product's lifehowever, the recovery of these requires an infrastructure and technology for recycling. Similarly, failure to recycle obsolete products means that these products are disposed of, usually in sanitary landfills, thus consuming another resource-land. Thus, concerns about resource depletion have directly led to the focus upon product recycling.

The issue of the rate of resource extraction was the subject of significant studies in the early and mid-twentieth century. The work of Hotelling ${ }^{14}$ and Solow ${ }^{15}$ largely demonstrate that, in the absence of substantial market imperfections, the market mechanism is sufficient to lead to efficient rates of resource extractionpurely through price setting. Setting aside elements of government policies which distort resource prices in order to achieve other social ends, it is difficult to argue with this theory of resource extraction or the empirical evidence supporting it. What, then, accounts for the fact that real prices of resources have declined, while the Hotelling theories predict increases in prices according to the rate of intertemporal equity?

There are several technical explanations for this trend. One is the steady improvement in the efficiency of extraction-many ores mined today are of a grade that could not be exploited economically 50 years ago. Another is the decreased material intensity in products. Materials have prices; engineers strive to reduce costs by reducing the amount of material they use - examples include the declining mass of the automobile, the consequences of microelectronics upon consumer products, and the miniaturization of many machines 
and tools. By decreasing the degree of materials intensity, the magnitude of material demand has fallen, leading to reduced material prices. Furthermore, materials science has increasingly demonstrated that substitutes for almost any material can be found; substitutes increase competition and enlarge the stock of resources available for the future, both of which exert downward forces on material prices. Thus, the evolution of materials and design technologies has more than offset the natural rate of material price increase that would otherwise have been observed. And this rate of advance shows no sign of slackening, suggesting that resource depletion is unlikely to be a concern over the next 50-100 years.

If this is so, why is recycling such a "hot" topic? While there are many possible explanations, it is clear that recycling has achieved considerable political currency, driven first by the German initiatives of the mid-1990s, followed by the initiatives of the European Union (EU). These institutions plan to establish recycling targets, requiring producers to assure that specified rates of resource recovery will be achieved. What is interesting is that many of these recycling initiatives are focused upon industries where recycling already takes place at relatively high rates. For example, the automobile (one of the pending EU targets) is already processed within a fully market-driven resource-recovery infrastructure, achieving recovery rates in excess of $75 \%$ by mass. Today's EU targets for vehicle recycling are not particularly onerous, either technically or economical$1 y,{ }^{16}$ but they do seem to emphasize approaches to recycling that are potentially less technically efficient in order to satisfy political concerns-not to mention imposing requirements that may ultimately challenge the ability of producers to meet other environmental objectives.

Nevertheless, recyclability has become a new design target in many industries. The extent to which products will actually be recycled depends upon the economics of recycling and recovery, and the markets for secondary materials, but it is clear that recyclability starts with careful consideration of the materials employed in the manufacture of a product, the ways in which they are combined, and the technologies that exist to segregate them. Each of these considerations falls squarely within the domain of materials specification, and thus recycling has become one of the key metrics of the environmental merits of a product.

\section{Emissions}

While recycling has emerged from a combination of resource depletion and landfill consumption concerns, life cycle measurements have most generally focused upon the emissions that are consequential to product manufacture, use, and disposal. The notion of emissions is very general in this context, encompassing all chemical species that are released to the air, water, and land as a result of the manufacture of a product. In the strictest sense, landfill would also be defined as an emission, although the issues of recycling and resource conservation have tended to overshadow this perspective in most cases.

Although much of the theoretical work in the life cycle community remains focused upon establishing the relationship between emissions to the environment and environmental quality, the so-called "precautionary principle" has led to the generally accepted notion that less emissions are preferable to more emissions. In principle, the perspective that it is always preferable to reduce emissions should lead to an overall reduction in the environmental effects of manufactured goods. However, while this approach is an attractive starting point, its practical implementation immediately confronts the designer with the hard realities of emission profiles. Just as there is no continuum of material performance that would allow the designer to select the precisely necessary material for an application, there is no continuum of emission profiles associated with alternative designs. This fact means that, in general, there is no single alternative that minimizes release of all possible chemical species. Consequently, just as designers are obliged to trade off engineering performance across a number of domains, the development of an "environmentally sound" product confronts the designer with the problem of trading off emissions performance across several chemical species. While designers are not qualified environmental engineers, it is difficult to establish these tradeoffs in practice, particularly since the legislative and regulatory models under which they operate tend to focus on absolute reduction of all emissions, rather than suggesting that some emissions may be more damaging than others.

The problem of emissions reduction is further compounded by the fact that many of these emissions are chemically active and, as a consequence, interact with each other in complex ways-the interaction of nitrogen oxides and hydrocarbon to form photochemical smog is an example. Smog signals the formation of ground-level ozone, which has substantial health effects upon the human respiratory system. While it is true that absolute reductions in both nitrogen oxides and airborne hydrocarbons will reduce the rate of ozone formation, it is not the case that only reducing one of the two will reduce the rate; in fact, such a reduction might actually increase it.

As a consequence, the engineering design community has devised a range of strategies to take environmental effects into account. At one extreme, life cycle analyses of emissions are simply ignored or are given minimum priority on the grounds that they are incomplete, technically limited, and uncoordinated with conventional project assessment methods (e.g., cash flows and engineering performance). At the other extreme is the effort to make the most of available data, even if limited, and to try to establish the relative importance of certain emissions. Examples of this approach include the Scandinavian environmental priority strategies system, used by Volvo, and the Dutch and Swiss Eco-Indicator systems. ${ }^{17}$ These tools rely on complex weighting systems that yield a single metric of environmental performance; this is then used to rank alternative designs, essentially creating a new engineering metric of performance. The success with which the methods have fully characterized the entire environmental consequences of a product is easily challenged, limiting their acceptability. More limited methods have been developed in the consulting and academic environments-Newell's ${ }^{17}$ extended life cycle analysis method is one example. They exploit the fact that, in general, the requirement is for a comparative, rather than an absolute, allowing firmer conclusions to be drawn from limited data.

In practice, of course, most designers currently operate somewhere between these two extremes. The predominant approach has been to focus upon a handful of emissions, and attempt to manage the ways in which products contribute to the total release of these species. Today, the focus tends to be upon greenhouse gases, particularly $\mathrm{CO}_{2}$, whose effects are being given increasingly more importance each day it seems. Other target emissions included smog precursors and particulate matter, largely because of their demonstrated effects on human health. Life cycle inventories which suggest that one alternative can reduce these releases are given considerable currency, and are frequently employed in ways that the developers of life cycle analysis would never have countenanced, including product marketing to the public.

However, LCA itself is still a tool in the early stages of its development, and there remain a host of conceptual puzzles 
which will only be resolved through careful assessment of its implications, even when only a single chemical species is being assessed.

Thus, while life cycle analysis does provide the design engineer with a useful platform for environmental assessment of products, its utility is circumscribed by the fact that it remains a developing method whose maturity is still far off. Designers are in the unenviable position of being given a great deal of data describing aspects of the environmental effects of products (and thus, the materials employed in their manufacture) without a satisfactory way to trade off these effects against one another. As a result, automobile designers are confronted with recycling requirements that essentially outlaw (or make prohibitively expensive) the use of advanced lightweight composite materials, even though these materials could drastically reduce the amount of greenhouse gases released to the atmosphere. In the absence of environmental policy guidance that takes the need for these tradeoffs into account, designers will attempt to apply their own judgment, compounded by their employers' strategic objectives, to select the material that satisfies some of these environmental criteria. However, this effort will remain unsatisfying to all concerned until the concept of trading off environmental effects is given the same credence as that of trading off engineering and economic performance.

\section{Aesthetics and Industrial Design}

As products mature technically and markets saturate, sales are maintained through industrial design and differentiation; product design relies upon this. As one president of Sony put it: "Desire, not need, is the motive force of the market."

In such a market, materials are chosen for their perceived attributes and associations as well as for their technical attributes. Figure 9 illustrates the relationships. A product (central circle) is designed to meet a set of specifications. These include not only its function, but also its target consumer group: men, women, the elderly, teenagers, children, sports participants, and so forth. Each group has different needs and tastes. A successful product satisfies both.

To make the product, materials are shaped, joined, and finished by processes (left-hand circles); together they generate what might be called the "physiology" of the product, its physical existence and functionality. The shape, color, and style are created to appeal to the tastes and suggest the associations desired by the chosen

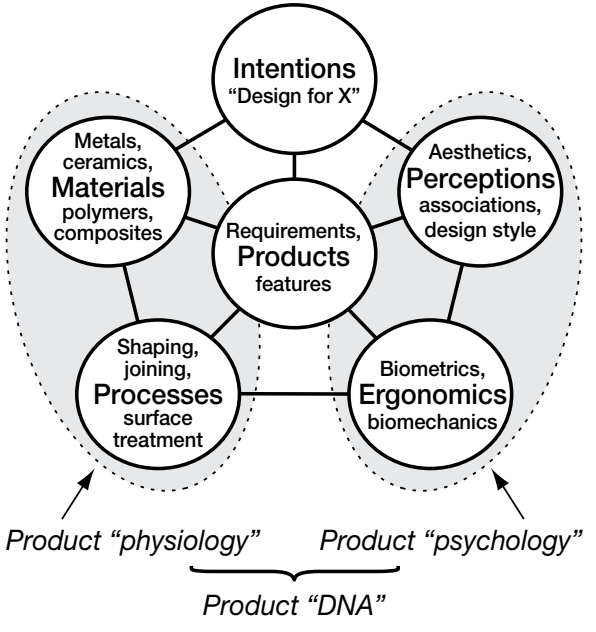

Figure 9. Product character is the combination of its physical and its perceived attributes: its "physiology" and its "psychology."

consumer group-associations of safety and durability, for instance, or of delicacy, or of light-hearted-in ways that are detailed by authors such as Billington, ${ }^{18}$ Faste, ${ }^{19}$ Pye, ${ }^{20}$ and Jordan..$^{21}$ We shall refer to the aesthetic or industrial-design qualities of a product as its perceived attributes (upper-right circle), thereby distinguishing them from the physical attributes associated with function, material, and process. Finally, ergonomics (lower-right circle) concerns the ways in which the product matches the physical and mental capabilities and limitations of the user; their importance in increasing efficiency, safety, and user satisfaction has led to a separate literature and to the development of specialized design methods to achieve them. ${ }^{22}$ Taken together with the perceived attributes, these form what might be called the "psychology" of the product, its deeper character. The full attribute profile defines what might be called the genetic code of the product; it is the "product DNA."

Materials and processes are chosen to give a desired set of perceived attributes. Polished wood, one might say, has associations of warmth, tradition, and quality; metals generally have a functional flavor; plastics, to some people, are cheap, cheerful and disposable; composites have an aura of high technology. These are generalizations, and they are poor ones. Figure 9 makes the point that, almost always, the link between perceived attributes and material is via the product itself. The associations created by the use of wood in fine furniture (tradition, luxury, quality) are quite different from those associated with its use to make, say, a bicycle (primitive, low technology, archaic). But although the influence is indirect, the choice of material and process plays a central role in industrial design and in the creation of a desired cluster of perceived attributes.

It has been argued in the past, and the argument is still sometimes used today, that a product designed to function properly will automatically have aesthetic appeal; that "form follows function." This reasoning leads to the view that industrial design as an active pursuit is unnecessary, since good technical design will produce it as a by-product. There is a counterargument: that unattractive products have merely been "engineered," that they lack real "design." A more realistic view is that both the technical design and the industrial design of a product influence the consumers' choices. There are many reasons for taking the role of industrial design seriously, of which the following examples are relevant here.

\section{Product Maturity}

Many products, typified by household appliances, consumer goods, automobiles, and many electronics, are now technically mature. Distinctions in technical performance no longer really exist and the prices of products with approximately the same performance vary little. Differentiation, in the eyes of consumers, then lies in the industrial design of the product; it is this that decides their choice.

\section{Corporate and Brand Identity}

The image carried by a corporation and its products is one of its most valuable assets; indeed, the principal asset of some companies is their brand name. Creating and presenting this image and carrying it from one generation of products to the next is a function of industrial design that touches every aspect of the company: its products, its advertising, and even the architecture of its buildings. Empires, armies, religious orders, airlines, railways, manufacturing corporations-all of these use design to convey what they are like (or how they would like to appear) to the outside world. In short, industrial design creates and maintains corporate and brand identity.

\section{The Environment}

Products are part of the environment in which we live. Mass production now supplies products to a far larger market and in far larger volumes than in the earlier days of craft-based design, when few could afford them. In this sense mass production has enhanced the quality of life, but in others it has the capacity to diminish it. Massproduced products become part of the 
environment in which we live: the TV set in every living room, the car outside every house. Our environment is enhanced if these products satisfy, but if products create expectations that are not fulfilled, add nothing to (or even detract from) selfesteem or sense of place in society, or give no sense of satisfaction, then the quality of life has suffered.

Successful product design depends on a balanced mix of technical and industrial design. This fact has been more readily accepted in architecture than in engineering-architects speak of the three "ideals" of efficiency, economy, and elegance. ${ }^{18}$ There is an increasing awareness that similar ideals apply to product design, and specifically to the use of materials in design. ${ }^{20}$ For these reasons and others, industrial design is now as important an aspect of the total design process as any other and it is one of the major drivers of both material and process development of the 21st century.

\section{Economics and Business Strategy}

For many material and product selection decisions, the designers do have final authority. This may not be the case for decisions that are likely to have large financial or strategic consequences. For example, in the automobile industry, designers in advance engineering groups usually make decisions about material choices for applications like headlights and bumper systems. When it comes to material choices for automotive bodies, a higher level of the organization is usually involved. This involvement is not a reflection upon the competence of the designers; rather, it is a reflection of the fact that there are dimensions of the product development cycle that derive from considerations that are outside of their direct knowledge or experience. One of the most important factors is the firm's ownership of usable capital equipment. For instance, new materials are often financially viable when an analysis is conducted on a "greenfield" basis (i.e., new investment is required for all competitive materials), but are at a cost disadvantage when the analysis does not require investment in plant and/or equipment for the existing material. Increased outsourcing, of course, changes this; it is always possible to move the source to one with capabilities with a new material or process.

There are many illustrations of this fact of the engineering designer's life. To return to the automobile bumper discussion cited earlier for an example, all of the bumpers under consideration were socalled "aerodynamic" bumpers, colored and contoured to match the automobile body lines. The shape and color scheme was dictated by the body styling designers; had these same designers decided that the marketplace was likely to respond more positively to a so-called "bright" bumper (i.e., with a shiny, metallic-plated finish), none of the polymeric-intensive alternatives would have even been considered. Another example might be the decision to employ magnesium or aluminum in a die casting; given the extensive investment of several automotive companies in magnesium extraction and production facilities, it may well be that there are strategic interests that will favor magnesium usage, even if aluminum might be a better match for the designer's criteria. Finally, there is the example of engineering scope. Many product designs are subdivided into smaller, if not simpler, units according to established rules within the firm. The rules for this subdivision embed a series of engineering constraints to be met in order to successfully bring these subunits together to yield a product meeting overall product performance goals, goals which may not even be an explicit part of the specification of any single subunit. These systemic performance targets, achievable only when all the units are assembled, can easily overrule design choices that may look perfectly reasonable at the unit design level. For example, automobile occupant safety is the result of a complex set of performance features embedded throughout the vehicle. Only a decision-maker at the pinnacle of the product development process is able to perform the necessary balance of performance of each of the vehicle subunits necessary to achieve a specified level of performance.

Thus, there are a host of strategic variables, driven by the imperatives of the business environment and the complexities of product development, that will directly influence (and potentially override!) the selection and specification of material by the engineering teams within a firm.

Finally, all investment in a new product involves risk. Some industries are riskaverse-the nuclear industry, the civil engineering sector and, increasingly, the aerospace sector. Others are not-the sports equipment sector, interior designers, and the designers of consumer products eagerly seize upon new materials and processes and readily accept products made from them.

Risk preference has significance for new material development. Developing, qualifying, and commercializing a new structural material takes, typically, 15 years, and it is not always obvious that it will be technically or economically viable when that point is reached. In the last century much of the development cost of structural materials was underwritten by governments through defense, space, and nuclear programs willing to invest on such a time scale - one that private industry is unwilling to accept. For functional materials the time scale can be shorter, and partly because of their immaturity, their potential value can be higher, making them a more attractive investment opportunity.

\section{Conclusions}

Nothing is static. We seek to optimize materials to meet today's needs, but before the optimization is complete, the boundary conditions-meaning the underlying drivers for material development-change, requiring redirection of the development.

The dominant drivers of the early 21st century differ markedly from those of the late 20th. The priorities of defense, nuclear power, and space have been displaced by those associated with economic growth, knowledge management, and health care. The globalization of industry and internet commerce throw heavier emphasis on economic attributes of materials, on the value of intellectual property, and on business strategy. Prosperity and product maturity give industrial design and the perceived attributes of products and materials a higher priority. And we have, in one regard, over-reached ourselves, creating the need to adapt design, and materials that are central to it, to restore equilibrium with the environment.

All these influence the direction of materials development. The maturity of most structural materials-a priority of the last century-and the drive for smaller size, greater functionality, and the replacement of products by services throws emphasis on the less mature study of nonstructural attributes of materials: electrical, optical, magnetic, and biological. Many of these are properties of thin films, of surfaces, or of interfaces. Surfaces, too, play a key role in the perceived attributes: color, texture, feel, and the associations that materials carry; these play an increasingly central role in successful product design. Environmental concerns direct attention to the ecological attributes of materialsthe demand they make on the resource base and the environmental load created by their production, use, and disposal-a systems problem, requiring a systems analysis solution; but it is clear that renewable materials, recyclability, and life extension (requiring sophisticated methods of residual life assessment) can all contribute. And finally there is the business case- the economics and strategy of development and deployment. 


\section{Acknowledgments}

The ideas described here owe a great deal to our colleagues and particularly to Dr. Ulrike Wegst, Elicia Maine, and Kara Johnson. We wish to acknowledge the support of the Körber Foundation and of the UK EPSRC through the Engineering Design Centre at Cambridge.

We thank the Materials Systems Laboratory and MIT (industrial consortium) for support and Drs. Richard Roth and Randolph Kirchina for ideas and discussions.

\section{References}

1. R.L. Keeney and H. Raiffa, Decisions With Multiple Objectives: Preferences and Value Tradeoffs (John Wiley \& Sons, New York, 1976). 2. F.R. Field and R. de Neufville, "Materials Selection-Maximizing Overall Utility," Metals Mater. 4 (6) (1988).

3. R. Roth, F. Field, and J. Clark, "Materials Selection and Multi-Attribute Utility Analysis," J. Comput.-Aided Mater. Design 1 (3); ESCOM Science Publishers, Leiden, The Netherlands; October, 1994, p. 325.

4. R. Kirchain and F. Field, "Process-Based Cost-Modeling: Understanding the Economics of Technical Decisions," in Encyclopedia of Materials Science and Engineering (Elsevier, Oxford) (in press)

5. J.P. Clark, R. Roth, and F.R. Field, “Techno- economic Issues in Material Science", ASM Handbook Vol. 20, Materials Selection and Design, (ASM International, Materials Park, OH, 1997). 6. J.V. Busch and F.R. Field, III, "Technical Cost Modeling," Chapter 24 of the Blow Molding Handbook, D. Rosato and D. Rosato, eds.; (Hansr Publishers, New York, 1988).

7. M.F. Ashby, A.G. Evans, N.A. Fleck, L.J. Gibson, J.W. Hutchinson, and H.N.G. Wadley, Metal Foams: A Design Guide (ButterworthHeinemann, Woburn, MA, 2000).

8. E. Maine and M.F. Ashby, "Cost and Viability," Adv. Eng. Mater. 2 (4) (2000) p. 205.

9. For example, see J. Horgan, The End of Science (Abacus Books, Little, Brown Co., London, UK, 1996).

10. For example, see D.H. Meadows, D.L. Meadows, J. Randers, and W.W. Behrens, (1972) The Limits to Growth-1st Report of the Club of Rome (Universe Books, New York, 1972). 11. For example, see E. von Weizsäcker, A.B. Lovins, and L.H. Lovins, Factor Four, (Earthscan Publications, London, 1997).

12. F. Schmidt-Bleek, How Much Environment Does the Human Being Need-Factor 10-The Measure for an Ecological Economy (Deutscher Taschenbuchverlag, Munich, 1997).

13. "SETAC, A Technical Framework for Life-Cycle Assessment," (Society of Environmental Toxicology and Chemistry, Washington, DC, 1991)

14. H. Hotelling, "The Economics of Exhaustible Resources," J. Polit. Econ. 39 (1931), p. 137.
15. R. Solow, "The Economics of Resources or the Resources of Economics," Am. Econ. Rev. 2 (64) (1974), p. 1.

16. M.-F. Hong, "Implications of Regulation and Policy on Economics of Vehicle Recycling," unpublished SM thesis, Massachusetts Institute of Technology, 2000

17. S.A. Newell, "Strategic Evaluation of Environmental Metrics: Making Use of Life Cycle Analysis," unpublished PhD thesis, Massachusetts Institute of Technology, 1998.

18. D.P. Billington, The Tower and the Bridge, New Art of Structural Engineering (Princeton University Press, Princeton, 1985).

19. R.A. Faste, "The Role of Aesthetics in Engineering," Japan. Soc. of Mech. Eng. J., 28 (1995), p. 385.

20. D. Pye, The Nature and Aesthetics of Design (Cambium Press, Connecticut, 1997).

21. P.W. Jordan, Designing Pleasurable Products (Taylor \& Francis, London, 2000).

22. For example, see C.H. Flurscheim, ed., Industrial Design in Engineering (The Design Council, London, 1983).

M.F. Ashby is from the Engineering Design Center in the Engineering Department at Cambridge University.

J.P. Clark is from the Materials Systems Laboratory at the Massachusetts Institute of Technology.

F.R. Field III is from the Materials Systems Laboratory at the Massachusetts Institute of Technology.

\section{What will the century uncover in materials?}

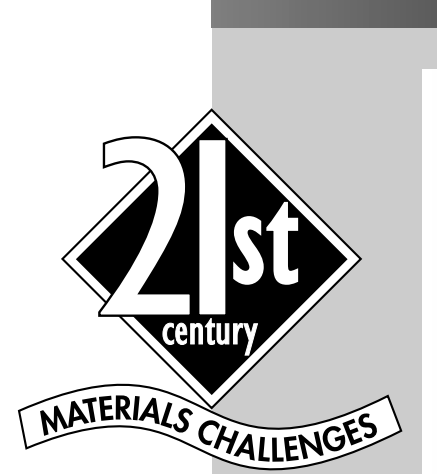

"Habitat: Sensors may be used to measure wind speeds or earthquake-generated pressures and provide for a temporary increase in strength at anchorage points of the roof and other vulnerable locations."

"We look forward to the tube of biomedical 'glue' which we simply squeeze on to a cut to seal and heal it."

"Many of our human parts will be replaced with better materials: bearts, lungs, and kidneys that never wear out, only needing a tune-up from time to time."

"A single disk with a petabit of storage would provide approximately a movie a day for over 60 years."

"Cities may be built under the sea for security, with access to fish farms and photosynthetic harvests."

\section{What do you think?}

Send in a Letter to the Editor with your ideas of Materials Challenges for the Next Century:

Gditor, MaS Bulletin, 506 Keystone Prive, Uarrendale, PA 15086-7573

fax: 724-779-8313 • Bulletin@mrs.org • www.mrs.org/publications/bulletin/21steen/ 